\title{
EN TORNO AL CONCEPTO DE IDEOLOGÍA
}

Daniel Miguel López Rodríguez

Universidad de Sevilla

Resumen.-

Palabras clave:

\section{Concerning the concept of ideology}

Abstract.-

\section{Keywords:}

\section{La ideología y las ideas}

En un principio el término uideología» se presentó bajo el significado de "ciencia de las ideası entre los filósofos materialistas franceses de finales del siglo XVIII. Estos filósofos apelaban al sensualismo al pensar que las ideas procedían de las sensaciones (por lo que se posicionaban desde una especie de formalismo primogenérico, propio del «materialismo vulgar»). Estos filósofos eran principalmente Destutt de Tracy, Étienne Bonnot de Condillac, Pierre-Jean-Georges Cabanis, Claude-Adrien Helvetius, el conde de Volney, Emmanuel-Joseph Siéyes...

El término ideología puede entenderse, entonces, como sistema de ideas, lo que vendría a significar lo mismo que filosofía, dado que el objeto propio de la filosofía (y no de las ciencias) son las Ideas, puesto que el papel de la filosofía en el conjunto del saber consiste en relacionar y sistematizar las conexiones y desconexiones que hay entre las mismas. Aunque, en rigor, no existe "la» filosofía, pues «las» filosofías son muy diversas y se piensan necesariamente unas frente a otras para poder constituirse y posicionarse.

Pero la filosofía (al menos la filosofía materialista) no es una ideología; y las ideologías -como las verdades científicas, las técnicas y la situación política- son 
materiales para la reflexión filosófica, es decir, para la crítica filosófica (si entendemos la filosofía como un saber de segundo grado que reflexiona objetivamente sobre saberes de primer grado). Aunque también cabría decir que si toda filosofía es de algún modo una ideología ello no quiere decir que toda ideología sea filosófica, pues también podría ser de naturaleza mitológica o religiosa.

Según Marx, las ideologías son formas socializadas de "falsa conciencia» y creencias constitutivas del mundo real; son, pues, "formaciones nebulosas» que dependen de determinadas condiciones materiales aun siendo ideas que no se corresponden con la realidad. Las ideologías, más que sistemas plenamente organizados, son nubes de creencias que al delimitar su contorno están enfrentadas a otras nubes de creencias, y en tal confrontación dialéctica se desencadena una tormenta que influye directamente en la política real. "La moral, la religión, la metafísica y cualquier otra ideología y las formas de conciencia que a ellas corresponden pierden, así, la apariencia de su propia sustantividad. No tienen su propia historia ni su propio desarrollo, sino que los hombres que desarrollan su producción material y su intercambio material cambian también, al cambiar esta realidad, su pensamiento y los productos de su pensamiento. No es la conciencia la que determina la vida, sino la vida la que determina la conciencia»'!

Una ideología se nutre entonces de un material de ideas dado, material que a su vez es moldeado y transformado, ya que toda corriente ideológica tiende a crecer y desarrollarse frente a otras corrientes ideológicas, de acuerdo con aquella máxima que reza pensar es pensar contra alguien o contra algo (y si esto no es posible entonces sencillamente no se piensa). Aunque, en rigor, el método ideológico no consiste en partir del objeto mismo sino en las concepciones que de él nos formamos, es decir, la realidad se deduce no de sí misma sino de la imaginación.

La religión, como es el caso de la religión cristiana en sus diferentes confesiones, se presenta como la ideología por antonomasia (por no hablar del judaísmo, del islam o de refluencias de las religiones secundarias como la ufología o el espiritismo). La religión cristiana es interpretada como una ideología en el sentido de la falsedad absoluta, puesto que tiene la pretensión de revelar el sentido absoluto de la historia universal al profetizar la salvación del Género Humano (así como su condenación eterna en el valle de azufre y fuego para los impíos y malvados). La religión cristiana se presenta como confidente de la divinidad, al afirmar que ha recibido un mensaje de la divinidad, que ha recibido una revelación especial; cosa que va contra la racionalidad, pues se pretende ser portavoz de un mensaje de salvación recibido a través de una intuición praeterracional (aunque se plasme en algo tan material como el papel de la Biblia o en el cuerpo de la Iglesia militante). La ideología religiosa podría recuperar la vieja fórmula atribuida a Tertuliano y proclamar: credo quia absurdum.

Pero la racionalidad y los saberes están moldeados desde instituciones históricas y

1 Karl Marx y Friedrich Engels, La ideología alemana, Akal, Traducción de Wenceslao Roces, Madrid 2014, Pág. 21. 
antropológicas que se han forjado dialécticamente, dependientes de la cultura extrasomática y de naturalezas impersonales, así como de los seres situados en el eje angular del espacio antropológico, esto es, seres personales o personeiformes finitos y corpóreos pero que no son humanos (al menos si nos situamos desde un espacio antropológico tridimensional y no desde un espacio antropológico bidimensional, como era el de Hegel con la distinción Naturaleza y Espíritu o el de Marx con la distinción Naturaleza e Historia).

Como dijo Plejánov, «El origen, cambio y destrucción de la asociación de ideas, bajo la influencia del origen, cambio y destrucción de ciertas combinaciones de fuerzas sociales, explica en alto grado la historia de la ideología»². Se ha dicho también que la ideología no es una verdad objetiva, ni tampoco un error, "sino algo que puede convertirse en verdadero mediante la Lucha y el Trabajo, que propiciarán que el Mundo se adecue al ideal. La prueba de la Lucha y el Trabajo vuelve verdadera o falsa una ideología. Al final del proceso revolucionario observaremos que lo que se ha realizado no es la pura y simple ideología de la que partimos, sino algo diferente y que es la verdad ("realidad revelada") de esta ideología»" "Con la propaganda, toda ideología se convierte en otra cosa distinta a la que es; se vuelve impura y mentirosay4. Asimismo, se ha sostenido que la ideología no es uuna aberración o una excrecencia contingente de la Historia: constifuye una estructura esencial en la vida histórica de las sociedades»15.

Según Marx, una ideología es el reflejo del movimiento aparente de las cosas (una apariencia falaz, diríamos) en la conciencia de los agentes de la producción, y asimismo una imagen invertida de la realidad; pues la ideología pone al mundo "cabeza abajo». Así, "ulas ideologías se alimentan de este reflejo del movimiento aparente y lo elaboran conscientemente, haciendo de él sistemas doctrinalessib. Por tanto «la ideología no viene a ser simple reflejo pasivo de la realidad aparente en la conciencia; la ideología tiene un papel activo en el desarrollo de una clase; ella contribuye a darle una cohesión más fuerte; ella juega un papel en defensa de sus intereses; es en la ideología donde una clase toma conciencia de sí misma. Es por ello por lo que uno de los aspectos de toda lucha de clases se encuentra en la "Iucha ideológica", contra las construcciones que tienden a dar un valor universal a la ideología del adversario»». Así «los hombres viven de ideología, es en la ideología donde ellos encuentran su coherencia interna, sus razones de ser y actuar; es en la ideología (y en la organización política) donde una clase se constituye en clase; la ideología pues no es una creación secundaria, superflua, exterior: sin ideología una clase social pierde toda su cohesión, toda su fuerza; por ello la ideología es "vivida": un individuo (o una clase) cree profundamente en su ideología; los burgueses de 1789 creyeron realizar realmente el reino universal de la

\footnotetext{
2 Citado por Bujarin, N. I., Teoría del materialismo histórico, Traducción de Pablo de la Torriente Brau, Grabriel Barceló y María Teresa Poyrazián, Siglo XXI, Madrid 1974, Págs. 322-323.

3 Alexander Kojève, Introducción a la lectura de Hegel, Traducción de Andrés Alonso Martos, Editorial Trotta, Madrid 2013, Pág. 160.

4 Íbid., Pág. 180.

5 Louis Althusser, La revolución teórica de Marx, Traducción de Marta Harnecker, Siglo XXI, México D. F., Madrid y Buenos Aires 1976, Pág. 193.

6 Jean Guichard, El marxismo. Teoría y práctica de la revolución, Traducción de José María Llanos, Editorial Española Desclée de Brouwer, Bilbao 1975, Pág. 356.

7 Íbid., Pág. 358.
} 
fraternidad, de la igualdad y de la libertad»8. "La ideología será entonces el dominio de los "valores" morales, de las creencias, de las filosofías; el dominio o terreno de los sueños, de las esperanzas, de las utopías en nombre de las cuales el hombre dice lo que hace, y sin las cuales él no hace absolutamente nada; es necesario a todo hombre, a toda clase, a toda sociedad dar de este modo un sentido a su existencia»?.

Los ideólogos, al igual que los sofistas de la antigua Grecia que criticó Platón (ser preso de una ideología sería como estar en la caverna que criticaba Platón), son fabricantes de apariencias (de apariencias falaces); aunque -como se ha dicho«la apreciación subjetiva de los ideólogos no debe confundirse con su función objetiva» ${ }^{10}$.

\section{La conciencia falsa}

Lo que Marx, en última instancia, viene a decir con el término «ideología» es la "falsa conciencia» (aunque sería más correcto hablar de "conciencia falsa», porque una «falsa conciencia» no es una conciencia, es una pseudoconciencia, y lo que se quiere a dar a entender es una conciencia que es falsa, es decir, que tiene un contenido falso pero que es conciencia). Luego se podría decir que el ideólogo no es un filósofo sino más bien un filodoxo, así como un adoctrinador y un predicador. Según Marx, la conciencia falsa es encubridora de la explotación, por lo que «ideología» tiene más bien un sentido peyorativo. La conciencia falsa es aquella que se sitúa en una posición en la que es incapaz de corregir sus errores, es por ello un cerrojo (un cerrojo ideológico, diríamos). Aunque sólo cabe hablar de conciencia falsa cuando los contenidos de dicha conciencia, que se tomaban como válidos, sean triturados o absorbidos por contenidos más potentes que puedan reducir al absurdo a los anteriores, pues éstos son contenidos de una conciencia deformada.

La conciencia falsa es falsa porque se representa lo que no es, se representa o representa contra los demás lo irreal. Las ideologías son por tanto como formas de engaño y de autoengaños colectivos. La conciencia falsa se hace más abstracta y errónea mientras más brille en ella la evidencia o la certeza práctica, aunque el "consenso de las conciencias» sea prácticamente universal. Un ejemplo de esto es la evidencia que tuvieron durante siglos los hombres de que la Tierra era el centro del universo y que el Sol giraba alrededor de la Tierra. Pero se trataba de una evidencia que en realidad era errónea y abstracta por mucho que estuviese consensuada universalmente, como demostró la revolución copernicana.

Como le escribía Engels a Franz Mehring el 14 de julio de 1893, "La ideología es un proceso que el llamado pensador cumple conscientemente, es cierto, pero con una conciencia falsa. Las verdaderas fuerzas motrices que lo impulsan le permanecen desconocidas, pues de lo contrario no sería un proceso ideológico. Porque es un proceso mental, deriva su forma y su contenido del pensamiento

\footnotetext{
8 Íbid., Pág. 362-363.

9 Íbid., Pág. 363.

10 Nikolai Bujarin, Teoría del materialismo histórico, Traducción de Pablo de la Torriente Brau, Grabriel Barceló y María Teresa Poyrazián, Siglo XXI, Madrid 1974, Pág. 305.
} 
puro, sea el suyo propio o el de sus predecesores. Trabajo con material meramente intelectual, que acepta sin examen como producto del pensamiento, no investiga buscando un proceso más lejano, independiente del pensamiento; su origen le parece evidente, porque como todo acto se verifica por intermedio del pensamiento, también le parece estar basado en última instancia sobre el pensamiento. El ideólogo que trata de historia (entiendo aquí por historia simplemente todas las esferas -la política, la jurídica, la filosófica, la teológicapertenecientes a la sociedad y no sólo a la naturaleza) posee en cada dominio científico una documentación formada independientemente en el pensamiento de generaciones anteriores y que ha atravesado una serie independiente de desarrollos en los cerebros de esas generaciones sucesivas. Es verdad que los hechos exteriores pertenecientes a su esfera propia 0 a otras pueden haber ejercido una influencia codeterminante sobre este desarrollo, pero se presupone tácitamente que esos hechos son a su vez solamente frutos de un proceso intelectual, de modo que seguimos estando dentro de ese reino del pensamiento puro, que ha digerido con éxito los hechos más tercosıl ${ }^{11}$.

La ideología, como conciencia falsa, viene a ser un concepto similar a la necesidad de la concatenación de las ideas inadecuadas o confusas que Espinosa formuló en la Ética: «La falsedad consiste en la privación del conocimiento que implican las ideas inadecuadas o mutiladas y confusası ${ }^{12}$. También cabría corresponderla con los Idola fori o Idola Theatri de los que hablaba Francis Bacon.

Para Gustavo Bueno, las ideologías son nebulosas de creencias configuradas mediante programas que actúan sobre materiales dados, materiales que vienen a ser ortogramas, los cuales pueden actuar como prejuicios con capacidad moldeadora pero también como un sistema de axiomas fértiles. Y, como bien se ha dicho, uhay que tener en cuenta que el error no es un criterio suficiente para hablar de falsa conciencia, un científico puede equivocarse, pero ello no es prueba de su falsa conciencia, más bien, será una prueba de la falsa conciencia la actitud operatoria que se tome ante el errorı ${ }^{13}$.

Las ideologías, siempre que se entienda como "conciencia falsa», vendrían a corresponderse con lo que Gustavo Bueno llama mitos tenebrosos, esto es, mitos oscurantistas y confusionarios. Y precisamente, como sostiene Bueno, el papel de la filosofía en el conjunto del saber consiste en triturar esos mitos tenebrosos que acechan a las conciencias (a los sujetos operatorios humanos objetiva y racionalmente institucionalizados) por todas partes, a raíz de la disputa no solamente filosófica sino además política, científica, artística y religiosa. Frente a los mitos tenebrosos Bueno opone los mitos luminosos (y un buen ejemplo de ello es el que podríamos llamar "el mito fundacional de la filosofía»: el mito de la caverna que expone Platón en el libro VII de la República). Se podría decir que los mitos oscurantistas y confusionarios son propios de la reacción o el status quo y los mitos

\footnotetext{
11 Karl Marx y Friedrich Engels, Sobre la religión, Edición preparada por Hugo Assmann y Reyes Mate, Ágora, Salamanca 1974, Pág. 453.

12 Baruch de Espinosa, Ética, Traducción de Atilano Domínguez, Biblioteca de los grandes pensadores, Barcelona 2004, Pág. 103.

13 Pablo Huerga, La ciencia en la encrucijada, Pentalfa Ediciones, Oviedo 1999, Pág. 155.
} 
luminosos propios de la revolución o la reacción ante el orden vigente (pero no siempre es así).

Si la teoría no coincide con la práctica entonces es una conciencia falsa, al tratarse de mera palabrería sin correlato realmente existente; por lo tanto, para huir del engaño y acercarnos al desengaño, teoría y práctica tienen que coincidir; es decir, en la «interpretación» del mundo están las claves de su «transformación», pero si dicha interpretación no transforma el mundo entonces es una conciencia falsa, la cual viene a ser un «tejido conceptual o perceptual enfermo» ${ }^{14}$.

La conciencia falsa no reconoce las contradicciones y además se esfuerza por ocultarlas (esto se correspondería con la impostura). Así, la conciencia falsa será «el atributo de cualquier sistema de ortogramas en ejercicio tal que pueda decirse de él que ha perdido la capacidad "correctora" de sus errores, puesto que cualquier material resultará asimilable en el sistema. Según nuestras premisas, esta atrofia de la capacidad "autocorrectora" sólo podrá consistir en el embotamiento para percibir los mismos conflictos, limitaciones o contradicciones determinados por los ortogramas en ejercicio, eventualmente en la capacidad para envolverlos o encapsularlos en su curso global. Es obvio que los mecanismo efectivos que llevan a este embotamiento (al menos cuando se trata de las grandes formaciones ideológicas), no son tanto psicológicos o individuales (derivados de patologías desviaciones de personalidad) cuanto sociales y políticosı ${ }^{15}$. Es decir, el embotamiento ideológico (o cerrojo ideológico) no es propio de una locura subjetiva, que podría ser subsanada con medicinas o tratamiento médico, sino de una locura objetiva, que sería propio de ser tratada para su remedio o corrección desde una filosofía capacitada para desactivar hipóstasis metafísicas y mitos tenebrosos que funcionan como ideologías dominantes del presente en marcha, es decir, como conciencias falsas objetivamente implantadas a fin de engordar determinados intereses en detrimento de otros intereses.

No obstante, la ideología no consiste meramente en una conciencia falsa, no se agota en ser una imagen distorsionada y torcida de la realidad; pues la ideología bien puede ser el propio quehacer de la realidad social. Por eso la "“ideología" es una realidad social cuya existencia implica el no conocimiento de sus participantes en lo que se refiere a su esencia» ${ }^{16}$. En la ideología, quiero decir, en el funcionamiento institucional de ésta, los individuos no saben lo que hacen, pero es en ese hacer donde está lo ideológico. «Es una cuestión -afirma Žižek - de discordancia entre aquello que la gente efectivamente hace y aquello que piensa que hace», porque el que está preso de las garras de la ideología, visto así, «no sabe lo que en realidad hace $)^{17}$. Sin embargo, Žižek reinterpreta la fórmula marxiana afirmando que la ilusión no está de parte del saber, sino de la realidad efectiva, no de lo que la gente piense o diga, sino de lo que realmente hace. La conducta de la gente se torna, pues, ideológica. La ideología no es simplemente una teoría, también es una praxis. La actividad de la gente está marcada, por

\footnotetext{
14 Gustavo Bueno, Cuestiones cuodlibetales sobre Dios y la religión, www.fgbueno.es/med/dig/gb89cc00, Mondadori, Madrid 1989, Pág. 393.

15 Íbid., Pág. 394.

16 Slavoj Žižek, El sublime objeto de la ideología, Traducción de Isabel Vericat Núñez, Siglo XXI, Madrid 2010, Pág. 47,

17 Íbid., Pág. 58.
} 
tanto, por una ilusión, "ppor una inversión fetichista» ${ }^{18}$. Por eso, para Marx la verdad no está en los que los hombres piensen, imaginen o digan de sí mismos, sino en lo que realmente hagan (aunque decir ya es, de algún modo, hacer, pues -como se ha dicho- también es posible «hacer cosas con palabras»).

Es más, "Los hombres se han forjado hasta la fecha representaciones falsas sobre sí mismos, sobre lo que son o lo que deberían sen> ${ }^{19}$. Visto desde el proletariado industrial: ellos saben que la libertad burguesa, aquella libertad en la que los obreros optan libremente por vender su fuerza de trabajo porque si no la otra opción sería morirse de hambre, es una libertad que encubre la explotación y los abusos, pero aun así son favorables a esta idea de libertad y siguen votando a los partidos políticos burgueses o aburguesados que los explotan enmascaradamente (a veces descaradamente). El comunismo, con vistas a la revolución que traería la victorial final del proletariado y en consecuencia la emancipación del Género Humano, traerá a los obreros la auténtica representación de lo que realmente son.

Según Žižek, la ideología no consiste en ser una ilusión o un sueño que nosotros mismo construimos para escabullirnos de la soporífera realidad laboral (algo así como el opio que -según decía Marx refiriéndose a la religión- el pueblo se administra a sí mismo para hacer más leve y llevadera su miseria en este mundo terrenal). "Una ideología "se apodera de nosotros" realmente sólo cuando no sentimos ninguna oposición entre ella y la realidad -a saber, cuando la ideología consigue determinar el modo de nuestra experiencia cotidiana de la realidad $\rangle^{20}$. Es decir, la ideología está instalada en nuestra vida real y moldea nuestro comportamiento. Y, si la cosa funciona, la ideología se incorpora a nuestra vida y de este modo nos negamos a quitarnos las vendas que nos desideologicen. «No lo saben, pero lo hacenı ${ }^{21}$.

Para Lenin, por su parte, el término «ideología» no significaba necesariamente "conciencia falsa», pues todo depende del contenido de determinada ideología y la ideología socialista y revolucionaria era la que él y los suyos intentaban inculcar a los obreros; y el socialismo, lejos de ser una «conciencia falsa» era, a su juicio, una conciencia verdadera.

\section{La ideología de la clase dominante}

Lo que, en última instancia, Marx quería destapar era la ideología de la clase dominante de su tiempo, es decir, quería desvelar la auténtica idiosincrasia de la clase burguesa, y tras dicho desvelo o desenmascaramiento destruirla y edificar sobre sus ruinas la sociedad socialista y, en última instancia, comunista. Sociedad futura en la que el hombre no explotará al hombre porque estará desalienado al no haber ideologías que oculten la verdad.

\footnotetext{
18 íbid, Pág. 61.

19 Karl Marx, Textos selectos, Traducción de Jacob Muñoz Veiga, Javier Pérez Royo, José María Ripalda Crespo, Manuel Sacristán Luzón y León Mames, Gredos, Madrid 2012, Pág. 47.

20 Slavoj Žižek, El sublime objeto de la ideología, Traducción de Isabel Vericat Núñez, Siglo XXI, Madrid 2010, Pág. 80.

21 Karl Marx, El Capital. Crítica de la economía política, Libro I: El proceso de producción del capital, Traducción de Pedro Scaron, Biblioteca de los grandes pensadores, Barcelona 2003, Pág. 75.
} 
Marx criticó sin piedad a toda concepción de la política que encubría intereses de clase ligados a fuerzas en absoluto «idealistas». Por ello redefinió el término «ideología» imprimiéndole un significado sociológico dialéctico, entendiendo así a las ideologías como formaciones propias de unos grupos sociales enfrentados a otros grupos sociales; es decir, las ideologías son conceptos e ideas que emplean determinados grupos o clases sociales para justificar sus posiciones frente a otros grupos o clases sociales. Las ideologías al estar socialmente arraigadas tienen inexorablemente un componente dialéctico y en consecuencia polémico al pensarse unas ideologías contra otras, porque -como ya hemos advertido- pensar es pensar contra alguien. Y pensar es pensar objetivamente en torno a y por mediación de la materia determinada de la que partimos en nuestro regressus crítico triturador al que corresponde una vuelta a los fenómenos o progressus que los racionalice, pero no siempre de modo pacífico y amistoso, sino también violento e incluso sanguinario (al menos en la polémica ciudad de los hombres, no ya en la armoniosa ciudad de Dios y de sus ángeles celestiales puramente espirituales).

Las ilusiones ideológicas van tomando cuerpo a raíz de la división del trabajo en manual e intelectual. En cuanto se investigan los modos y relaciones de producción y las relaciones sociales que se dan tras dicha producción, inmediatamente se investigan las ideologías que se van configurando (ya de manera consciente o inconsciente), comprendiéndose que la clase dominante se impone material y espiritualmente frente a la dominada, conservando así sus intereses de clase, pues -como ya hemos anotado-para Marx lo importante y relevante no es lo que los hombres digan o piensen sino lo que efectivamente hagan.

La conciencia falsa y deformada recae sobre las conciencias enclasadas que están determinadas por las relaciones de producción. "Las ideas de la clase dominante son las ideas dominantes en cada época; o, dicho en otros términos, la clase que ejerce el poder material dominante en la sociedad es, al mismo tiempo, su poder espiritual dominante. La clase que tiene a su disposición los medios para la producción material dispone con ello, al mismo tiempo, de los medios para la producción espiritual, lo que hace que se le sometan, al propio tiempo, por término medio, las ideas de quienes carecen de los medios necesarios para producir espiritualmente. Las ideas dominantes no son otra cosa que la expresión ideal de las relaciones materiales dominantes, las mismas relaciones materiales dominantes concebidas como ideas; por tanto, las relaciones que hacen de una determinada clase la clase dominante son también las que confieren el papel dominante a sus ideas. Los individuos que forman la clase dominante tienen también, entre otras cosas, la conciencia de ello y piensan a tono en ello; por eso, en cuanto dominan como clase y en cuanto determinan todo el ámbito de una época histórica, se comprende de suyo que lo hagan en toda su extensión y, por tanto, entre otras cosas, también como pensadores, como productores de ideas, que regulen la producción y distribución de las ideas de su tiempo; y que sus ideas sean, por ello mismo, las ideas dominantes de la épocaı ${ }^{22}$. Vemos que, en

22 Karl Marx y Friedrich Engels, La ideología alemana, Akal, Traducción de Wenceslao Roces, Madrid 2014, Pág. 39. 
terminología hegeliana, la ideología dominante vendría a ser el «Espíritu de la Época» (Zeitgeist).

Marx interpreta la maquinaria del Estado como un instrumento en manos de la clase dominante, la cual con su poder encubre la división y conflicto entre las diferentes clases sociales y, a su vez, imponen la tendencia de la llamada «opinión pública»s. La ideología dominante enmascara y disimula las contradicciones, y al mismo tiempo oculta la forma de superar el modo de producción existente y ofrece soluciones falsas. La clase dominante presenta sus intereses particulares de clase como si éstos fuesen los intereses de la sociedad en general, y también actúa como si su ideología no estuviese condicionada por un contexto histórico determinado sino como si fuese una ideología eterna o dada in illo tempore. La clase dominante trata de hacer ver que sus intereses particulares coinciden con el interés general, y que sus ideas son por tanto las únicas que son racionales y de vigencia incontestable e irrebasable.

Es decir, la clase dominante impone su dogma como si éste fuese universal, hace de su ideología una ley universal, un imperativo categórico. Así, las clases dominantes estructuran las ideas convencionales en pos de sus intereses. "Los economistas proceden de una forma muy singular. Para ellos no hay más que dos tipos de instituciones, las del arte y las de la naturaleza. Las instituciones feudales son instituciones artificiales; las de la burguesía son instituciones naturales. En esto se parece a los teólogos, que también establecen dos tipos de religiones. Cualquier religión que no sea la suya, es un invento de los hombres, mientras que su propia religión es una emanación de Dios. Al decir que las relaciones actuales -las relaciones de producción burguesa-son naturales, los economistas dejan entrever que esas son las relaciones en las que se crea la riqueza y se desarrollan las fuerzas productivas de acuerdo con las leyes de la naturaleza. Por tanto, esas relaciones son en sí mismas unas leyes naturales independientes de la influencia del tiempo. Son leyes eternas que deben regir siempre a la sociedad. De esta forma, la historia existió durante un tiempo, pero ya no existe. Existió la historia puesto que existieron las instituciones feudales, y porque en esas instituciones feudales encontramos unas relaciones de producción completamente diferentes de las de la sociedad burguesa, que los economistas quieren hacer pasar por naturales y, por lo tanto, eternası ${ }^{23}$.

De modo que, como critica Marx, los economistas burgueses postulan la perennización de las leyes sociales y las interpretan como leyes naturales y por tanto divinas, porque vienen a postularse como leyes eternas y, en consecuencia, se defiende que es imposible el cambio puesto que lo natural es el statu quo. Cuando un ideólogo, como fue el señor Eugen Dühring, «cree estar construyendo una teoría de la moral y del derecho para todos los tiempos y todos los mundos, lo que hace en realidad es trazar una imagen caricaturesca -arrancada de su base real, invertida como en un espejo cóncavo- de las corrientes conservadoras o revolucionarias de su tiempo» ${ }^{24}$.

23 Karl Marx, Miseria de la filosofía, Traducción de Tomás Onaindia, Edaf, Madrid 2004, Págs. 220-221. 24 Friedrich Engels, Filosofía (Esquemática del mundo. Filosofía de la naturaleza. Moral y derecho. Dialéctica), Versión al español de Ediciones en Lenguas Extranjeras Moscú, Ediciones R. Torres, Barcelona 1976, Pág. 96. 
La Idea de Naturaleza -es decir, del mito tenebroso de la Naturaleza- tiene aquí un fuerte componente ideológico claramente favorable a los intereses de la clase dominante, pues viene a legitimar la absolutización y normalización del orden burgués. La burguesía alimenta al proletariado con "deseos piadosos», y su ideología dominante es el decorado que encubre la explotación. "Cuanto más capaz sea una clase dominante de incorporar a los hombres más eminentes de las clases dominadas, tanto más sólida y peligrosa será su dominación»25.

Por consiguiente, la ideología de la clase dominante, poseedora del poder material y espiritual, es decir, de los medios de producción y de los medios por los que puede difundir la superestructura ideológica, impone así un fenómeno de desrealización, ocultación y disimulo de las condiciones alienantes que hace que los dominados se imbuyan en una cierta pérdida de la realidad efectiva, siendo así presos del camelo idealista que beneficia a los dominadores, los cuales quieren que persevere el statu quo de la explotación y mantener así sus privilegios de clases, en detrimento de los explotados-alienados-pauperizados. La ideología de la clase dominante hace que los dominados y explotados vivan en una ilusión, en una borrosa deformación de la realidad, en una pseudorealidad; espejismo que hace que la clase dominante legitime y justifique sus privilegios. «Todos los fenómenos de deformación o inversión entrañan una cierta pérdida de la realidad, una adelgazamiento o una alteración esencial de la verdadera textura ontológica del mundo objetivo» ${ }^{26}$. En efecto, «la ideología religiosa del medievo por ejemplo-, con su concepción de una jerarquía cósmica que reflejaba el orden feudal, significaba que la explotación del siervo por el señor era disfrazada como una subordinación del siervo a sus superiores naturales bajo el gobierno de Diosı) ${ }^{27}$.

El poder ideológico estaría, pues, en manos de la clase dominante, y las ilusiones utópicas se forjarían en las clases dominadas, pues la gente feliz ni planea ni lleva a cabo revoluciones (ni tampoco escribe o espera apocalipsis). Pero como señala Puente Ojea, la realidad «nos ofrece algo muy diferente: todas las clases sociales, en una situación histórica dada, participan de la ideología dominante, aunque desde intereses opuestos y mentalidades diferentes. Lo que denomino horizonte utópico de la ideología es compartido tanto por las clases dominantes como por las clases dominadas, si bien para las primeras ese horizonte funciona como referencia legitimadora de unos privilegios, mientras que para las segundas opera como explicación de su actual condición subordinada y, a la vez, como garantía de la expectativa de una satisfacción final de aspiraciones insatisfechas en el presenter ${ }^{28}$.

En la lucha de clases no sólo se da el enfrentamiento entre los miembros de una clase contra los de otra clase diferente, sino también se dan enfrentamientos entre

25 Karl Marx, El Capital. Crítica de la economía política, Libro III: El proceso global de la producción capitalista, Traducción de León Mames, Biblioteca de los grandes pensadores, Barcelona 2003, Pág. 629,

26 Gonzalo Puente Ojea, Ideología e Historia. La formación del cristianismo como fenómeno ideológico, Siglo XXI, Madrid 2001, Pág. 20.

27 Karl Marx citado por Gonzalo Puente Ojea, Ideología e Historia. La formación del cristianismo como fenómeno ideológico, Siglo XXI, Madrid 2001, Pág. 21-22.

28 Gonzalo Puente Ojea, Ideología e Historia. La formación del cristianismo como fenómeno ideológico, Siglo XXI, Madrid 2001, Pág. 60-61. 
sujetos y grupos de sujetos de una misma clase, como pudo observar Marx en los enfrentamientos entre los proletarios ingleses contra los proletarios irlandeses, encuentro (o desencuentro) fomentado precisamente por las clases dominantes «a través de la prensa, el púlpito, las publicaciones humorísticas... En fin, por todos los medios que tienen a su disposición las clases dominantesı ${ }^{29}$.

Asimismo, uen la sociedad desgarrada por las contradicciones de clase nunca puede existir una ideología al margen de las clases ni por encima de las clasesı, de ahí que utodo lo que sea rebajar la ideología socialista, todo lo que sea alejarse de ella equivale a fortalecer la ideología burguesa» 30 .

\section{El crepúsculo de las ideologías como ejemplo de conciencia falsa}

Los velos de la ideología sólo pueden arrancarse -piensa Marx-con la fuerza de la revolución, por eso la crítica a la ideología venía a ser la reforma del entendimiento; porque -como le escribe a Arnold Ruge en septiembre de 1843unosotros no anticipamos dogmáticamente el mundo, pero a partir de la crítica del viejo pretendemos deducir el nuevoı ${ }^{31}$.

Si para Marx la conciencia falsa es reaccionaria entonces la conciencia verdadera es revolucionaria; porque la toma de conciencia de explotación además de las condiciones materiales que desarrollan los modos de producciónes el requisito imprescindible para llevar a cabo la revolución, que en última instancia y en definitiva es de lo que se trataba. De modo que la ideología vendría a ser la conciencia falsa con la que la clase dominante quiere ocultar la cruda realidad para evitar la sublevación de las clases oprimidas y -según el joven Marx«alienadas», esto es, para impedir la revolución. La ideología es, pues, la conciencia justificativa y legitimadora del régimen establecido que defiende la clase dominante que es dueña de los medios de producción.

La revolución proletaria vendría a liberar a los dominados del velo ideológico de los dominadores. En la sociedad futura, que Marx suponía que sería la sociedad comunista sin clases (y por consiguiente sin Estados), el concepto de ideología como conciencia falsa perdería su vigencia, puesto que para Marx el imperio de las ideologías se reduciría solamente al período de la prehistoria humana, puesto que en la verdadera historia humana llevada a cabo en esa sociedad desclasada (y desestatalizada) ya no habría revolución sino simplemente evolución; y, por lo tanto, ya no harían falta enmascaramientos ideológicos porque todo lo real empezará a ser racional y diáfano para los ciudadanos verdaderamente libres y emancipados de toda explotación. Aunque esto no quiere decir que la historia desemboque en un acabamiento definitivo, en un estado ideal perfecto de la humanidad: «La historia, al igual que el conocimiento, no puede encontrar jamás su remate definitivo en un estado ideal perfecto de la humanidad; una sociedad

29 Citado por Jonathan Sperber, Karl Marx. Una vida decimonónica, Traducción de Laura Sales Gutiérrez, Galaxia Gutenberg, Barcelona 2013, Pág. 385.

30 Vladimir Ilich Lenin, Obras completas, Tomo IV, Versión de Editorial Progreso, Akal Editor, Madrid 1976, Pág. 391

31 Karl Marx, "La cuestión judía», en los Anales franco-alemanes, Traducción de J. M. Bravo, Ediciones Martínez Roca, S.A., Barcelona 1970, Pág. 66. 
perfecta, un "Estado" perfecto, son cosas que sólo pueden existir en la imaginación; por el contrario: todos los estadios históricos que se suceden no son más que otras tantas fases transitorias en el proceso infinito de desarrollo de la sociedad humana, desde lo inferior a lo superior. Todas las fases son necesarias, y por tanto, legítimas para la época y para las condiciones que las engendran; pero todas caducan y pierden su razón de ser, al surgir condiciones nuevas y superiores, que van madurando poco a poco en su propio seno; tienen que ceder el paso a otra fase más alta, a la que también le llegará, en su día, la hora de caducar y perecerı $\rangle^{32}$.

Dice Puente Ojea citando a Engels: "Lla interpretación dialéctica de la historia impide radicalmente la visión escatológica, porque "esta filosofía dialéctica disuelve todas las nociones de verdad absoluta definitiva y de los correspondientes estadios absolutos de la humanidad", y "muestra la caducidad de todas las cosas y en todas las cosas" "l,33. Pero resulta, como reconoce a continuación Puente Ojea, que tanto Engels como Marx «tenían la firme intuición de encontrarse "al comienzo de la historia de la humanidad"ı. También Jesús de Nazaret, el visionario de Galilea, tenía la firme creencia de vivir al final de la era premesiánica, dado que su Sitz im Lebem se situaba (emic) al final de los tiempos de la impiadosa dominación romana que daría paso al inminente Reino de Yahvé en la tierra prometida, siendo así Israel el nuevo y definitivo Imperio Universal (el Sacro Imperio Judaico). ¿ No es acaso parecida esa división del fin de la prehistoria humana y el inicio de la verdadera historia humana que predicaban Marx y Engels a la división de la era premesiánica de impiedad y dominación extranjera y la era mesiánica de piedad y dominación de Israel contra los impíos que predicaban Juan el Bautista y Jesús de Nazaret? Y que conste que mostrando el parecido no queremos postular la identidad, ya que hay obvias semejanzas pero también importantes diferencias.

No me parece, pensando contra Puente Ojea, que la interpretación dialéctica de la historia del marxismo impida radicalmente la visión escatológica, pues żno es acaso escatológico postular para el futuro una sociedad sin clases y sin Estados en la que "cada uno da según sus capacidades» y "a cada uno se le da según sus necesidades» sin que exista ninguna impostura ideológica que impida la verdadera realización del ser humano, es decir, sin trabas hacia la esperada «emancipación»? ¿Es que acaso en la sociedad comunista futura ya no habrá mitos tenebrosos por triturar? En ese caso sería el fin de la filosofía, la llamada «realización de la filosofía», que ya esbozó el joven Marx en 1843 en la «Contribución a la crítica de la filosofía del derecho de Hegel» en los Anales franco-alemanes.

Sostiene Puente Ojea: «El aspecto diferencial básico consiste en que mientras la ideología en sentido marxista strictu sensu es el producto de la conciencia alienada, la ideología de una sociedad sin clases es el resultado del esfuerzo analítico de una conciencia real y de la voluntad teleológica plenamente consciente y dueña de sí en el contexto de una reflexión científicamente

32 Friedrich Engels, Discurso ante la tumba de Marx, Editorial Progreso, http://www.marx2mao.com/M2M(SP)/M\&E(SP)/SGKM83s.html, Moscú 1981, Pág. 357-358.

33 Gonzalo Puente Ojea, Ideología e Historia. La formación del cristianismo como fenómeno ideológico, Siglo XXI, Madrid 2001, Pág. 47. 
fundada ${ }^{34}$. ¿ ${ }^{\text {No }}$ suena todo esto a una escatología de la racionalidad científica delirando objetivamente sobre una plenitudo temporis en la que se consagra una mathesis universalis, en sintonía con el fundamentalismo cientificista interdisciplinar? ¿No se vendría con esto a sustituir el fundamentalismo religioso por otro fundamentalismo, si cabe aún más peligroso, como es el fundamentalismo cientificista? El joven Marx insinuaba en sus manuscritos parisinos de 1844 algo así: «En un futuro la ciencia de la naturaleza será la ciencia del hombre y a la vez se hallará subsumida bajo ésta: no habrá más que una cienciar) ${ }^{35}$.

Esta escatología, que postula una ciencia que explique todo y el fin de la explotación del hombre por el hombre, hacen que Marx y Engels, más que los abanderados de un socialismo supuestamente científico, sean más bien los más consumados socialistas utópicos. El proletariado como clase universal que emanciparía al Género Humano fue sólo una conciencia falsa que la Gran Guerra y la Segunda Guerra Mundial (por no hablar del conflicto chino-soviético o de la propia caída de la Unión Soviética) pusieron en evidencia.

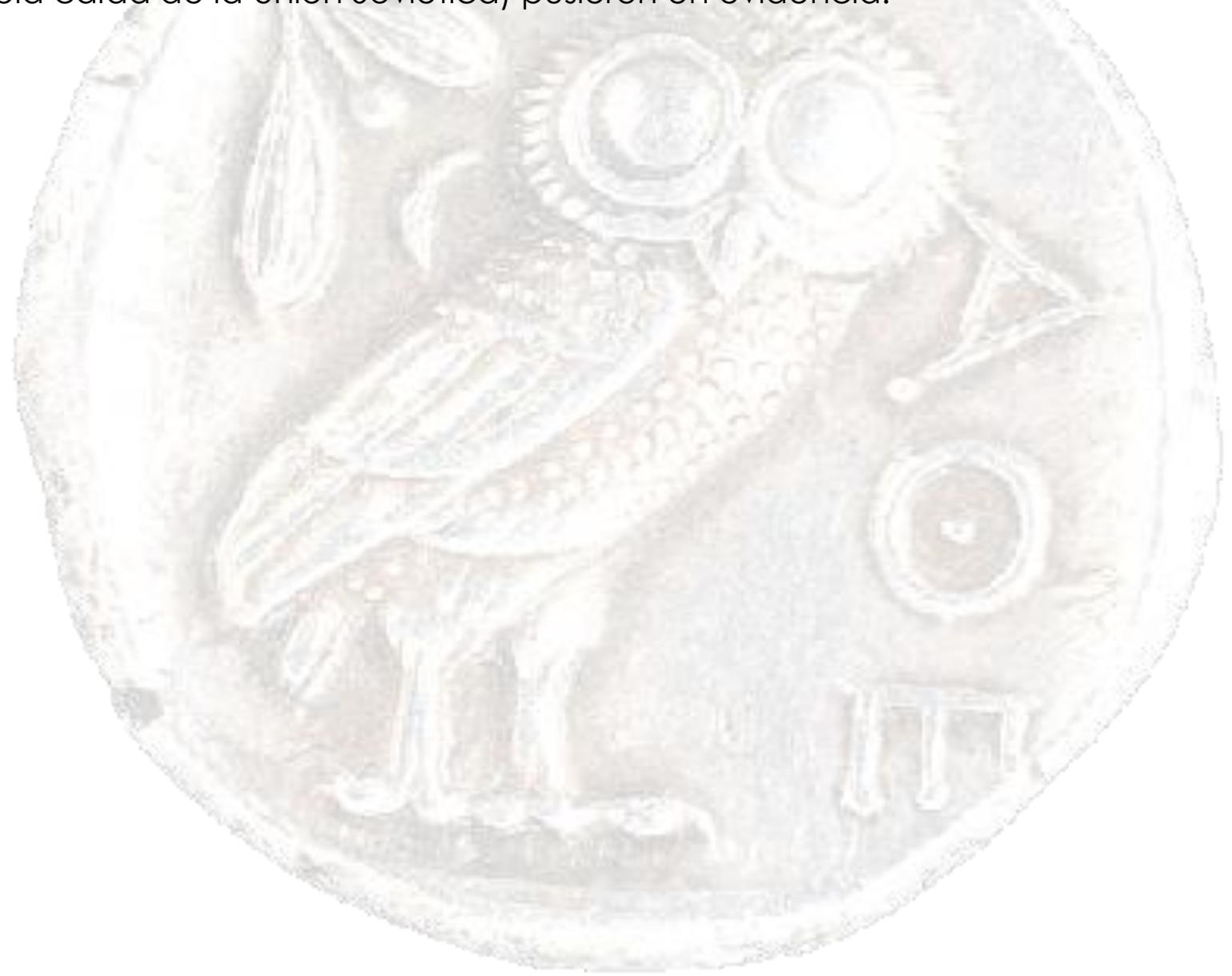

34 Íbid., Pág. 50.

35 Karl Marx, Manuscritos de París, Traducción de José María Ripalda Crespo, Gredos, Madrid 2012, Pág. 523. 